\title{
Existence result for a nonlinear fractional differential equation with integral boundary conditions at resonance
}

\author{
Shuqin Zhang ${ }^{1}$, Lei $\mathrm{Hu}^{1,2^{*}}$ and Ailing Shi ${ }^{3}$
}

\section{"Correspondence:}

huleimath@163.com

'Department of Mathematics, China

University of Mining and

Technology, Beijing, 100083, China

${ }^{2}$ School of Science, Shandong

Jiaotong University, Jinan, 250357,

China

Full list of author information is

available at the end of the article

\begin{abstract}
In this paper, we establish the existence result for nonlinear fractional differential equations with integral boundary conditions at resonance by means of coincidence degree theory. As applications, three examples are presented to illustrate the main results.
\end{abstract}

\section{Introduction}

In this paper, we prove the existence of solutions for fractional differential equations at resonance with integral boundary conditions given by

$$
\left\{\begin{array}{l}
D_{0^{+}}^{\alpha} u(t)=f\left(t, u(t), D_{0^{+}}^{\alpha-1} u(t), \ldots, D_{0^{+}}^{\alpha-(n-1)} u(t)\right), \quad 0<t<1, \\
u(0)=u^{\prime}(0)=\cdots=u^{n-2}(0)=0, \\
u(1)=(\alpha+m) \int_{0}^{1} t^{m} u(t) d t,
\end{array}\right.
$$

where $0<t<1, n-1<\alpha<n, m \in \mathbb{N}, D_{0^{+}}^{\alpha}$ is the Riemann-Liouville fractional derivative, and $f:[0,1] \times \mathbb{R} \rightarrow \mathbb{R}$ is a continuous function.

During the last few years, fractional differential equations have been studied extensively due to their significant applications in various sciences such as physics, mechanics, chemistry, phenomena arising in engineering. See [1-3] and the references therein. Many researchers paid attention to the existence of boundary value problems for nonlinear fractional differential equations, see [4-8]. The authors obtained the results by using the classical tools for such problems including the Leray-Schauder nonlinear alternative theorem, etc. Recently, there have been some papers devoted to the theory of fractional differential equations with integral boundary conditions, see [9-11].

In [9], Cabada and Wang studied the integral boundary value problem for nonlinear fractional differential equations:

$$
\left\{\begin{array}{l}
{ }^{C} D_{0^{+}}^{\alpha} u(t)+f(t, u(t))=0, \quad 0<t<1, \\
u(0)=u^{\prime \prime}(0)=0, \\
u(1)=\lambda \int_{0}^{1} u(s) d s,
\end{array}\right.
$$

@2013 Zhang et al.; licensee Springer. This is an Open Access article distributed under the terms of the Creative Commons Attribution License (http://creativecommons.org/licenses/by/2.0), which permits unrestricted use, distribution, and reproduction in any medium, provided the original work is properly cited. 
where $2<\alpha<3,0<\lambda<2,{ }^{C} D_{0^{+}}^{\alpha}$ is the Caputo fractional derivative and $f:[0,1] \times$ $[0,+\infty) \rightarrow[0,+\infty)$ is a continuous function. The author established sufficient conditions for the existence of nonlinear fractional differential equations with an integral boundary problem.

In [10], Yuan discussed an $(n-1,1)$-type semipositone integral boundary value problem for the coupled system of fractional differential equations

$$
\left\{\begin{array}{l}
D_{0^{+}}^{\alpha} u(t)+\lambda f(t, v(t))=0, \quad 0<t<1, \\
D_{0^{+}}^{\alpha} v(t)+\lambda g(t, u(t))=0, \quad 0<t<1, \\
u^{(j)}(0)=v^{(j)}(0)=0, \quad 0 \leq j \leq n-2, \\
u(1)=\mu \int_{0}^{1} u(s) d s, \quad v(1)=\mu \int_{0}^{1} v(s) d s,
\end{array}\right.
$$

where $\lambda, \mu$ are parameters and $\lambda>0,0<\mu<\alpha, \alpha \in(n-1, n], n \geq 3, D_{0^{+}}^{\alpha}$ is the RiemannLiouville fractional derivative, and $f, g:(0,1) \times[0,+\infty) \rightarrow \mathbb{R}$ are sign-changing continuous functions. Some existence results were given by using the Leray-Schauder nonlinear alternative theorem and the Krasnoselskii fixed point theorem.

In [11], Feng et al. considered a higher-order nonlinear nonlinear fractional differential equations with integral boundary conditions given by

$$
\left\{\begin{array}{l}
D_{0^{+}}^{\alpha} x(t)+g(t) f(t, x(t))=0, \quad 0<t<1, \\
x(0)=x^{\prime}(0)=\cdots=x^{(n-2)}(0)=0, \quad 0<t<1, \\
x(1)=\int_{0}^{1} h(t) x(t) d t,
\end{array}\right.
$$

where $0<t<1, n-1<\alpha \leq n, n \geq 3, D_{0^{+}}^{\alpha}$ is the Riemann-Liouville fractional derivative, and $g \in C((0,1),[0,+\infty))$ which may be singular at $t=0$ or (and) $t=1, h \in L^{1}[0,1]$ is nonnegative, and $f \in C([0,1] \times[0,+\infty),[0,+\infty))$ is a continuous function. By means of the Guo-Krasnoselskii fixed point theorem, some results on the existence of positive solutions are obtained.

At the same time, we notice that these problems happen to be at resonance if $\lambda=2$ in [9], $\mu=\alpha$ in [10] or $\int_{0}^{1} h(t) t^{\alpha-1} d t=1$ in [11]. Though there has been an increasing interest in the study of the existence of solutions for fractional differential equations at resonance (see [12-17]), the corresponding theorem and applications to the fractional differential equations with integral conditions at resonance have not been investigated now. Motivated by the works above, we discuss the integral boundary value problems of fractional differential equations (1.1), which happen to be at resonance in the sense that the associated linear homogeneous boundary value problem

$$
\left\{\begin{array}{l}
D_{0^{+}}^{\alpha} u(t)=0, \quad 0<t<1, \\
u(0)=u^{\prime}(0)=\cdots=u^{n-2}(0)=0, \\
u(1)=(\alpha+m) \int_{0}^{1} t^{m} u(t) d t,
\end{array}\right.
$$

has $u(t)=c t^{\alpha-1}, c \in \mathbb{R}$ as a nontrivial solution.

The rest of this paper is organized as follows. In Section 2, we give some necessary notations, definitions and lemmas. In Section 3, we study the existence of solutions of (1.1) 
by the coincidence degree theory due to Mawhin [18]. Finally, three examples are given to illustrate our results in Section 4.

\section{Preliminaries}

In this section, we present the necessary definitions and lemmas from fractional calculus theory. These definitions and properties can be found in the literature. For more details, see $[1-3]$.

Definition 2.1 [1] The Riemann-Liouville fractional integral of order $\alpha>0$ of a function $f:(0, \infty) \rightarrow \mathbb{R}$ is given by

$$
I_{0+}^{\alpha} f(t)=\frac{1}{\Gamma(\alpha)} \int_{0}^{t}(t-s)^{\alpha-1} f(s) d s
$$

provided that the right-hand side is pointwise defined on $(0, \infty)$.

Definition 2.2 [1] The Riemann-Liouville fractional derivative of order $\alpha>0$ of a continuous function $f:(0, \infty) \rightarrow \mathbb{R}$ is given by

$$
D_{0^{+}}^{\alpha} f(t)=\frac{1}{\Gamma(n-\alpha)} \frac{d^{n}}{d t^{n}} \int_{0}^{t} \frac{f(s)}{(t-s)^{\alpha-n+1}} d s
$$

where $n-1<\alpha \leq n$, provided that the right-hand side is pointwise defined on $(0, \infty)$.

Lemma $2.1[1]$ Let $n-1<\alpha \leq n, u \in C(0,1) \cap L^{1}(0,1)$, then

$$
I_{0+}^{\alpha} D_{0+}^{\alpha} u(t)=u(t)+C_{1} t^{\alpha-1}+C_{2} t^{\alpha-2}+\cdots+C_{n} t^{\alpha-n},
$$

where $C_{i} \in \mathbb{R}, i=1,2, \ldots, n$.

Lemma 2.2 [1] If $\alpha>0, m \in \mathbb{N}$ and $D=d / d x$. If the fractional derivatives $D_{0+}^{\alpha} u(t)$ and $D_{0+}^{\alpha+m} u(t)$ exist, then

$$
D^{m} D_{0+}^{\alpha} u(t)=D_{0+}^{\alpha+m} u(t) .
$$

Lemma 2.3 [1] The relation

$$
I_{a+}^{\alpha} I_{a+}^{\beta} f(x)=I_{a+}^{\alpha+\beta} f(x)
$$

is valid in the case $\beta>0, \alpha+\beta>0, f(x) \in L_{1}(a, b)$.

Lemma 2.4 The relation

$$
\int_{0}^{r} I_{0+}^{\alpha} f(x) d x=I_{0+}^{\alpha+1} f(r)
$$

is valid in the case $\alpha>0, f(x) \in L_{1}(0, r), r \in \mathbb{R}^{+}$. 


$$
\begin{aligned}
\int_{0}^{r} I_{0+}^{\alpha} f(x) d x & =\frac{1}{\Gamma(\alpha)} \int_{0}^{r} \int_{0}^{t}(t-s)^{\alpha-1} f(s) d s d t=\frac{1}{\Gamma(\alpha)} \int_{0}^{r} \int_{s}^{r}(t-s)^{\alpha-1} f(s) d t d s \\
& =\frac{1}{\Gamma(\alpha)} \int_{0}^{r} f(s) \int_{s}^{r}(t-s)^{\alpha-1} d t d s=\frac{1}{\Gamma(\alpha)} \int_{0}^{r} f(s) \frac{(r-s)^{\alpha}}{\alpha} d s \\
& =I_{0+}^{\alpha+1} f(r) .
\end{aligned}
$$

Now let us recall some notation about the coincidence degree continuation theorem. Let $Y, Z$ be real Banach spaces, $L: \operatorname{dom} L \subset Y \rightarrow Z$ be a Fredholm map of index zero and $P: Y \rightarrow Y, Q: Z \rightarrow Z$ be continuous projectors such that $\operatorname{ker} L=\operatorname{Im} P, \operatorname{Im} L=\operatorname{ker} Q$ and $Y=\operatorname{ker} L \oplus \operatorname{ker} P, Z=\operatorname{Im} L \oplus \operatorname{Im} Q$. It follows that $\left.L\right|_{\operatorname{dom} L \cap \operatorname{ker} P}: \operatorname{dom} L \cap \operatorname{ker} P \rightarrow \operatorname{Im} L$ is invertible. We denote the inverse of this map by $K_{P}$. If $\Omega$ is an open bounded subset of $Y$, the map $N$ will be called $L$-compact on $\bar{\Omega}$ if $Q N(\bar{\Omega})$ is bounded and $K_{P, Q} N=K_{P}(I-Q) N$ : $\bar{\Omega} \rightarrow Y$ is compact.

Theorem 2.1 Let L be a Fredholm operator of index zero and $N$ be L-compact on $\bar{\Omega}$. Suppose that the following conditions are satisfied:

(1) $L x \neq \lambda N x$ for each $(x, \lambda) \in[(\operatorname{dom} L \backslash \operatorname{ker} L) \cap \partial \Omega] \times(0,1)$;

(2) $N x \notin \operatorname{Im} L$ for each $x \in \operatorname{ker} L \cap \partial \Omega$;

(3) $\operatorname{deg}\left(\left.J Q N\right|_{\operatorname{ker} L}, \Omega \cap \operatorname{ker} L, 0\right) \neq 0$, where $Q: Z \rightarrow Z$ is a continuous projection as above with $\operatorname{Im} L=\operatorname{ker} Q$ and $J: \operatorname{Im} Q \rightarrow \operatorname{ker} L$ is any isomorphism.

Then the equation $L x=N x$ has at least one solution in $\operatorname{dom} L \cap \bar{\Omega}$.

\section{Main results}

In this paper, we always assume the following conditions.

$\left(\mathrm{H}_{0}\right) \frac{1}{\Gamma(\alpha+1)} \neq(\alpha+m) \sum_{i=0}^{m}(-1)^{i} \frac{m !}{(m-i) !} \frac{1}{\Gamma(\alpha+2+i)}$.

In this section, we prove the existence results for (1.1). We use the Banach space $E=$ $C[0,1]$ with the norm $\|u\|_{\infty}=\max _{0 \leq t \leq 1}|u(t)|$. For $\alpha>0, n=[\alpha]+1$, we define a linear space

$$
Y=\left\{u \mid u, D_{0+}^{\alpha-i} u \in E, i=1,2, \ldots, n-1\right\} .
$$

By means of the line functional analysis theory, we can prove that $Y$ is a Banach space with the norm

$$
\|u\|_{Y}=\left\|D_{0+}^{\alpha-1} u\right\|_{\infty}+\cdots+\left\|D_{0+}^{\alpha-(n-1)} u\right\|_{\infty}+\|u\|_{\infty} .
$$

Define $L$ to be the linear operator from $Y$ to $E$ with

$$
\operatorname{dom}(L)=\left\{u \in Y \mid u(0)=u^{\prime}(0)=\cdots=u^{n-2}(0)=0 ; u(1)=(\alpha+m) \int_{0}^{1} t^{m} u(t) d t\right\}
$$

and

$$
L u=D_{0+}^{\alpha} u, \quad u \in \operatorname{dom}(L) .
$$


Define $N: Y \rightarrow E$ by

$$
N u(t)=f\left(t, D_{0^{+}}^{\alpha-1} u(t), \ldots, D_{0^{+}}^{\alpha-(n-1)} u(t)\right) .
$$

Then problem (1.1) can be written by $L u=N u$.

Lemma 3.1 The mapping $L: \operatorname{dom}(L) \subset Z$ is a Fredholm operator of index zero.

Proof It is clear that

$$
\operatorname{ker}(L)=\left\{c t^{\alpha-1}, c \in \mathbb{R}\right\} \cong \mathbb{R}^{1} .
$$

Let $x \in \operatorname{Im} L$, so there exists a function $u \in \operatorname{dom} L$ which satisfies $L u=x$. By Lemma 2.1, we have

$$
u(t)=I_{0+}^{\alpha} x(t)+c_{1} t^{\alpha-1}+c_{2} t^{\alpha-2}+\cdots+c_{n} t^{\alpha-n} .
$$

By $u(0)=u^{\prime}(0)=\cdots=u^{(n-2)}(0)=0$, we can obtain $c_{2}=\cdots=c_{n}=0$. Hence

$$
u(t)=I_{0+}^{\alpha} x(t)+c_{1} t^{\alpha-1} .
$$

By $u(1)=(\alpha+m) \int_{0}^{1} t^{m} u(t) d t$, we have

$$
\begin{aligned}
I_{0+}^{\alpha} x(1)+c_{1} & =u(1)=(\alpha+m) \int_{0}^{1} t^{m}\left[I_{0+}^{\alpha} x(t)+c_{1} t^{\alpha-1}\right] d t \\
& =(\alpha+m) \int_{0}^{1} t^{m} I_{0+}^{\alpha} x(t) d t+c_{1} \int_{0}^{1}(\alpha+m) t^{\alpha+m-1} d t \\
& =(\alpha+m) \int_{0}^{1} t^{m} I_{0+}^{\alpha} x(t) d t+c_{1} .
\end{aligned}
$$

Taking into account Lemma 2.2 and using integration by parts, we obtain

$$
\begin{aligned}
I_{0+}^{\alpha} x(1) & =(\alpha+m) \int_{0}^{1} t^{m} I_{0+}^{\alpha} x(t) d t=(\alpha+m) \int_{0}^{1} t^{m} d I_{0+}^{\alpha+1} x(t) \\
& =(\alpha+m)\left[\left.t^{m} I_{0+}^{\alpha+1} x(t)\right|_{0} ^{1}-m \int_{0}^{1} t^{m-1} I_{0+}^{\alpha+1} x(t) d t\right] \\
& =(\alpha+m)\left[I_{0+}^{\alpha+1} x(1)-m \int_{0}^{1} t^{m-1} d I_{0+}^{\alpha+2} x(t)\right] \\
& \ldots \\
& =(\alpha+m) \sum_{i=0}^{m}(-1)^{i} \frac{m !}{(m-i) !} I_{0+}^{\alpha+1+i} x(1) .
\end{aligned}
$$

On the other hand, suppose that $x \in E$ satisfies $I_{0+}^{\alpha} x(1)-(\alpha+m) \sum_{i=0}^{m}(-1)^{i} \frac{m !}{(m-i) !} I_{0+}^{\alpha+1+i} x(1)=$ 0 . Let $u(t)=I_{0+}^{\alpha} x(t)$, we can easily prove $u(t) \in \operatorname{dom}(L)$. 
Thus, we conclude that

$$
\operatorname{Im}(L)=\left\{x \in E \mid I_{0+}^{\alpha} x(1)-(\alpha+m) \sum_{i=0}^{m}(-1)^{i} \frac{m !}{(m-i) !} I_{0+}^{\alpha+1+i} x(1)=0\right\} .
$$

Consider the linear operators $Q: Z \rightarrow \mathbb{R}$ defined by

$$
Q x(t)=\sigma \cdot\left[I_{0+}^{\alpha} x(1)-(\alpha+m) \sum_{i=0}^{m}(-1)^{i} \frac{m !}{(m-i) !} I_{0+}^{\alpha+1+i} x(1)\right],
$$

where $\sigma=\left[\frac{1}{\alpha \Gamma(a)}-(\alpha+m) \sum_{i=0}^{m}(-1)^{i} \frac{m !}{(m-i) !} \frac{1}{\Gamma(\alpha+2+i)}\right]^{-1}$ and $Q x(t) \cong \mathbb{R}$.

Take $x(t) \in E$, then

$$
\begin{aligned}
Q(Q x(t)) & =\sigma \cdot\left[\left.I_{0+}^{\alpha} Q x(t)\right|_{t=1}-\left.(\alpha+m) \sum_{i=0}^{m}(-1)^{i} \frac{m !}{(m-i) !} I_{0+}^{\alpha+1+i} Q x(t)\right|_{t=1}\right] \\
& =\sigma \frac{1}{\sigma} Q x(t)=Q x(t) .
\end{aligned}
$$

We can see $Q^{2}=Q$.

For $x(t) \in Z, x(t)=x(t)-Q x(t)+Q x(t)$, one has $Q[x(t)-Q x(t)]=0$.

Therefore

$$
x(t)-Q x(t) \in \operatorname{Ker}(Q)=\operatorname{Im}(L), \quad Q x(t) \in \operatorname{Im}(Q) .
$$

That is to say,

$$
Z=\operatorname{Im}(L)+\operatorname{Im}(Q) .
$$

If $u \in \operatorname{Im}(L) \cap \operatorname{Im}(Q)$, so we have $u=c \in \mathbb{R}$.

Because of $u=c \in \operatorname{Im}(L)$, then

$$
\left.I_{0+}^{\alpha} c\right|_{t=1}-\left.(\alpha+m) \sum_{i=0}^{m}(-1)^{i} \frac{m !}{(m-i) !} I_{0+}^{\alpha+1+i} c\right|_{t=1}=0
$$

As a result $c \cdot \sigma=0$, we get $c=0$.

Then

$$
Z=\operatorname{Im}(L) \oplus \operatorname{Im}(Q) .
$$

Note that $\operatorname{Ind} L=\operatorname{dim} \operatorname{ker} L-\operatorname{codim} \operatorname{Im} L=0$. Then $L$ is a Fredholm mapping of index zero.

We can define the operators $P: Y \rightarrow Y$, where

$$
P u=\frac{1}{\Gamma(\alpha)} D_{0+}^{\alpha-1} u(0) t^{\alpha-1}
$$


For $u \in Y$,

$$
P(P u)=P\left(\frac{1}{\Gamma(\alpha)} D_{0+}^{\alpha-1} u(0) t^{\alpha-1}\right)=\frac{1}{\Gamma(\alpha)} D_{0+}^{\alpha-1} u(0) t^{\alpha-1}=P u .
$$

So we have $P^{2}=P$.

Note that

$$
\operatorname{Ker} P=\left\{u \in Y \mid D_{0+}^{\alpha-1} u(0)=0\right\} .
$$

Since $u=u-P u+P u$, it is easy to say $u-P u \in \operatorname{Ker}(P), P u \in \operatorname{Ker}(L)$. And $Y=\operatorname{Ker}(P)+\operatorname{Ker}(L)$. If $u \in \operatorname{Ker}(L) \cap \operatorname{Ker}(P)$, so $u=c_{1} t^{\alpha-1}$, we can derive $\left.D^{\alpha-1} c_{1} t^{\alpha-1}\right|_{t=0}=0$, so $c_{1}=0$. Then

$$
Y=\operatorname{Ker}(L) \oplus \operatorname{Ker}(P) .
$$

For $u \in Y$,

$$
\begin{aligned}
\|P u\|_{Y} & =\left\|D_{0+}^{\alpha-1} u\right\|_{\infty}+\cdots+\left\|D_{0+}^{\alpha-(n-1)} u\right\|_{\infty}+\|u\|_{\infty} \\
& =\frac{1}{\Gamma(\alpha)}\left|D_{0+}^{\alpha-1} u(0)\right| \cdot\left(\left\|t^{\alpha-1}\right\|_{\infty}+\left\|D_{0+}^{\alpha-1} t^{\alpha-1}\right\|_{\infty}+\cdots+\left\|D_{0+}^{\alpha-(n-1)} t^{\alpha-1}\right\|_{\infty}\right) \\
& =\left(\sum_{i=1}^{n-1} \frac{1}{\Gamma(i)}+\frac{1}{\Gamma(\alpha)}\right)\left|D_{0+}^{\alpha-1} u(0)\right| \\
& =a\left|D_{0+}^{\alpha-1} u(0)\right|,
\end{aligned}
$$

where $a=\frac{1}{\Gamma(\alpha)}+\sum_{i=1}^{n-1} \frac{1}{\Gamma(i)}$.

We define $K_{P}: \operatorname{Im} L \rightarrow \operatorname{dom} L \cap \operatorname{ker} P$ by $K_{p} x=I_{0+}^{\alpha} x$. For $x \in \operatorname{Im}(L)$, we have $L K_{p} x=$ $D_{0+}^{\alpha} I_{0+}^{\alpha} x=x$.

And for $u \in \operatorname{dom}(L) \cap \operatorname{Ker}(P)$, we have $D_{0+}^{\alpha-1} u(0)=0$. So the coefficients $c_{1}, \ldots, c_{n}$ in the expressions

$$
u=I_{0+}^{\alpha} D_{0+}^{\alpha} u(t)+c_{1} t^{\alpha-1}+c_{2} t^{\alpha-2}+\cdots+c_{n} t^{\alpha-n}
$$

are all equal to zero. Thus we obtain

$$
K_{p} L u=I_{0_{+}}^{\alpha} D_{0+}^{\alpha} u=u,
$$

which shows that $K_{p}=\left(L_{\mathrm{dom}(L) \cap \operatorname{Ker}(P)}\right)^{-1}$.

Again, for each $x \in \operatorname{Im}(L)$,

$$
\begin{aligned}
\left\|K_{p} x\right\|_{Y} & =\left\|I_{0+}^{\alpha} x\right\|_{Y}=\left\|I_{0+}^{\alpha} x\right\|_{\infty}+\left\|D_{0+}^{\alpha-1} I_{0+}^{\alpha} x\right\|_{\infty}+\cdots+\left\|D_{0+}^{\alpha-(n-1)} I_{0+}^{\alpha} x\right\|_{\infty} \\
& \leq\left(\sum_{i=1}^{n-1} \frac{1}{\Gamma(i+1)}+\frac{1}{\Gamma(\alpha+1)}\right)\|x\|_{\infty} \\
& \leq\left(\sum_{i=1}^{n-1} \frac{1}{\Gamma(i)}+\frac{1}{\Gamma(\alpha)}\right)\|x\|_{\infty} \\
& =a\|x\|_{\infty} .
\end{aligned}
$$


Lemma 3.2 [17] $F \subset C^{\mu}[0,1]$ is a sequentially compact set if and only if $F$ is uniformly bounded and equicontinuous. Here uniformly bounded means that there exists $M>0$ such that for every $u \in F$,

$$
\|u\|_{c^{\mu}}=\left\|D_{0+}^{\mu}\right\|_{\infty}+\cdots+\left\|D_{0+}^{\mu-(N-1)} u\right\|_{\infty}+\|u\|_{\infty}<M
$$

and equicontinuous means that $\forall \epsilon>0, \exists \delta>0$ such that

$$
\left|u\left(t_{1}\right)-u\left(t_{2}\right)\right|<\epsilon \quad\left(\forall t_{1}, t_{2} \in[0,1],\left|t_{1}-t_{2}\right|<\delta, \forall u \in F\right)
$$

and

$$
\left|D_{0+}^{\alpha-i} u\left(t_{1}\right)-D_{0+}^{\alpha-i} u\left(t_{2}\right)\right|<\epsilon \quad\left(\forall t_{1}, t_{2} \in[0,1],\left|t_{1}-t_{2}\right|<\delta, \forall u \in F, i=0,1, \ldots, N-1\right) .
$$

By Lemma 3.2 and standard arguments, the following lemma holds.

Lemma 3.3 $K_{p}(I-Q) N: Y \rightarrow Y$ is completely continuous.

For convenience, we use the following notations: $\rho_{0}=a A+2 a\|\varphi\|_{\infty} ; \rho_{i}=2 a\left\|\psi_{i}\right\|_{\infty}, i=$ $1,2, \ldots, n$. To obtain our main results, we need the following conditions.

$\left(\mathrm{H}_{1}\right)$ There exist functions $\varphi, \psi_{i}, \in E, i=1,2, \ldots, n$, such that for all $t \in[0,1]$,

$$
\left|f\left(t, x_{1}, x_{2}, \ldots, x_{n}\right)\right| \leq \varphi+\psi_{1}\left|x_{1}\right|+\psi_{2}\left|x_{2}\right|+\cdots+\psi_{n}\left|x_{n}\right|
$$

$\left(\mathrm{H}_{2}\right)$ There exists a constant $A>0$ such that for every $y \in \mathbb{R}$, if $\left|D_{0^{+}}^{\alpha-1} u(t)\right|>A$, for all $t \in$ $[0,1]$, then

$$
Q N u(t) \neq 0 \text {. }
$$

$\left(\mathrm{H}_{3}\right)$ There exists a constant $B>0$ such that, for each $c \in \mathbb{R}$ satisfying $|c|>B$, we have at least one of the following:

$$
c Q N\left(c t^{\alpha-1}\right)>0
$$

or

$$
c Q N\left(c t^{\alpha-1}\right)<0 \text {. }
$$

$\left(\mathrm{H}_{4}\right) \sum_{i=1}^{n} \rho_{i}<1$

Lemma 3.4 $\Omega_{1}=\{u \in \operatorname{dom}(L) \backslash \operatorname{Ker}(L) \mid L u=\lambda N u, \lambda \in[0,1]\}$ is bounded.

Proof For $u \in \Omega_{1}, L u=\lambda N u$, thus $\lambda \neq 0$. And $L u=\lambda N u \in \operatorname{Im}(L)=\operatorname{Ker}(Q)$, that is,

$$
\lambda Q N u(t)=0 .
$$

By $\left(\mathrm{H}_{2}\right)$, there exists a constant $t_{0} \in[0,1]$ such that $\left|D_{0+}^{\alpha-1} u\left(t_{0}\right)\right| \leq A$. 
Again, for $u \in \Omega_{1}$, then $(I-P) u \in \operatorname{dom}(L) \backslash \operatorname{Ker}(L)$ and $L P u=0$, thus from (3.5), we have

$$
\|(I-P) u\|_{Y}=\left\|K_{p} L(I-P) u\right\|_{Y}=\left\|K_{p} L u\right\|_{Y} \leq a\|L u\|_{\infty} \leq a\|N u\|_{\infty} .
$$

Now, by Lemma 2.2,

$$
\begin{aligned}
\left|D_{0+}^{\alpha-1} u(0)\right| & \leq\left|D_{0+}^{\alpha-1} u\left(t_{0}\right)\right|+\left|\int_{0}^{t_{0}} D_{0+}^{\alpha} u(s) d s\right| \leq\left|D_{0+}^{\alpha-1} u\left(t_{0}\right)\right|+\left|t_{0}\right| \max _{0 \leq t \leq t_{0}}\left|D_{0+}^{\alpha} u(t)\right| \\
& \leq\left|D_{0+}^{\alpha-1} u\left(t_{0}\right)\right|+\left\|D_{0+}^{\alpha} u(t)\right\|_{\infty} \leq A+\|L u\|_{\infty} \leq A+\|N u\|_{\infty},
\end{aligned}
$$

that is,

$$
\left|D_{0+}^{\alpha-1} u(0)\right| \leq A+\|N u\|_{\infty}
$$

From (3.4), we have

$$
\begin{aligned}
\|u\|_{Y} & =\|P u+(I-P) u\|_{Y} \leq\|P u\|_{Y}+\|(I-P) u\|_{Y} \\
& \leq a\left|D_{0+}^{\alpha-1} u(0)\right|+a\|N u\|_{\infty} \\
& \leq a\left(A+\|N u\|_{\infty}\right)+a\|N u\|_{\infty} \\
& \leq a A+2 a\|N u\|_{\infty} .
\end{aligned}
$$

By $\left(\mathrm{H}_{1}\right)$, we have

$$
\begin{aligned}
\|u\|_{Y} & \leq a A+2 a\|N u\|_{\infty} \\
& \leq a A+2 a\left\|f\left(t, u(t), D_{0^{+}}^{\alpha-1} u(t), D_{0^{+}}^{\alpha-2} u(t), \ldots, D_{0^{+}}^{\alpha-(n-1)} u(t)\right)\right\|_{\infty} \\
& \leq a A+2 a\left(\|\varphi\|_{\infty}+\left\|\psi_{1}\right\|_{\infty}\|u\|_{\infty}+\left\|\psi_{2}\right\|_{\infty}\left\|D_{0+}^{\alpha-1} u\right\|_{\infty}+\cdots+\left\|\psi_{n}\right\|_{\infty}\left\|D_{0+}^{\alpha-(n-1)} u\right\|\right) \\
& =\rho_{0}+\rho_{1}\|u\|_{\infty}+\rho_{2}\left\|D_{0+}^{\alpha-1} u\right\|_{\infty}+\rho_{3}\left\|D_{0+}^{\alpha-2} u\right\|_{\infty}+\cdots+\rho_{n}\left\|D_{0+}^{\alpha-(n-1)} u\right\|_{\infty} .
\end{aligned}
$$

By the definition $\|u\|_{Y}$, we can derive

$$
\|u\|_{\infty} \leq \frac{1}{1-\rho_{1}}\left(\rho_{0}+\rho_{2}\left\|D_{0+}^{\alpha-1} u\right\|_{\infty}+\rho_{3}\left\|D_{0+}^{\alpha-2} u\right\|_{\infty}+\cdots+\rho_{n}\left\|D_{0+}^{\alpha-(n-1)} u\right\|_{\infty}\right) .
$$

Hence, we have

$$
\begin{aligned}
& \left\|D_{0+}^{\alpha-1} u\right\|_{\infty} \leq \frac{1}{1-\rho_{1}-\rho_{2}}\left(\rho_{0}+\rho_{3}\left\|D_{0+}^{\alpha-2} u\right\|_{\infty}+\cdots+\rho_{n}\left\|D_{0+}^{\alpha-(n-1)} u\right\|_{\infty}\right), \\
& \vdots \\
& \left\|D_{0+}^{\alpha-(n-1)} u\right\|_{\infty} \leq \frac{\rho_{0}}{1-\rho_{1}-\rho_{2}-\cdots-\rho_{n}}:=M .
\end{aligned}
$$

It is easy to see $\left\|D_{0+}^{\alpha-1} v\right\|_{\infty}, \ldots,\left\|D_{0+}^{\alpha-(n-1)} v\right\|_{\infty}$ and $\|u\|_{\infty}$ are bounded. We can conclude that $\|u\|_{Y}$ is bounded. 
Lemma 3.5 $\Omega_{2}=\{u \in \operatorname{Ker}(L): N u \in \operatorname{Im}(L)\}$ is bounded.

Proof Let $u \in \operatorname{Ker}(L)$, so we have $u=c t^{\alpha-1}, c \in \mathbb{R}, t \in[0,1]$, and $N u \in \operatorname{Im}(L)=\operatorname{Ker}(Q)$, thus

$$
\lambda Q N u(t)=0 .
$$

By $\left(\mathrm{H}_{2}\right)$, there exist two constant $t_{0} \in[0,1]$ such that

$$
\left|D_{0+}^{\alpha-1} u\left(t_{0}\right)\right|=\left|D_{0+}^{\alpha-1} c t^{\alpha-1}\right|_{t_{0}}|=| c \Gamma(\alpha) \mid \leq A .
$$

It follows that $|c| \leq \frac{A}{\Gamma(\alpha)}$. Here, $\Omega_{2}$ is bounded.

Lemma 3.6 $\Omega_{3}=\{u \in \operatorname{Ker}(L): \lambda u+(1-\lambda) Q N u=(0,0), \lambda \in[0,1]\}$ is bounded.

Proof Let $u \in \operatorname{Ker}(L)$, so we have $u=c t^{\alpha-1}, c \in \mathbb{R}, t \in[0,1]$.

Thus

$$
\lambda c t^{\alpha-1}+(1-\lambda) Q N\left(t^{\alpha-1}\right)=0 .
$$

If $\lambda=0$, then $|c| \leq \frac{A}{\Gamma(\alpha)}$. If $\lambda=1$, we have $c=0$.

It follows that

$$
\lambda c^{2} t^{\alpha-1}+(1-\lambda) c Q N\left(t^{\alpha-1}\right)=0 .
$$

Thus from the first part of $\left(\mathrm{H}_{3}\right)$, then $|c| \leq B$. Here, $\Omega_{3}$ is bounded.

Remark 3.1 If the other parts of $\left(\mathrm{H}_{3}\right)$ hold, then the set $\Omega_{3}^{\prime}=\{u \in \operatorname{Ker}(L):-\lambda u+(1-$ $\lambda) Q N u=0, \lambda \in[0,1]\}$ is bounded.

Theorem 3.1 Suppose $\left(\mathrm{H}_{1}\right)-\left(\mathrm{H}_{3}\right)$ hold, then problem (1.1) has at least one solution in $Y$.

Proof Let $\Omega$ be a bounded open set of $Y$ such that $\bigcup_{i=1}^{3} \bar{\Omega}_{i} \subset \Omega$. It follows from Lemma 3.3 that $N$ is $L$-compact on $\Omega$. By Lemma 3.4, Lemma 3.5 and Lemma 3.6, we get:

(1) $L u \neq \lambda N u$ for every $(u, v) \in[(\operatorname{dom} L \backslash \operatorname{Ker} L) \cap \partial \Omega] \times(0,1)$,

(2) $N u \notin \operatorname{Im} L$ for every $u \in \operatorname{Ker} L \cap \partial \Omega$,

(3) Let $H((u, v), \lambda)= \pm \lambda I(u, v)+(1-\lambda) J Q N(u, v)$, where $I$ is the identical operator. Via the homotopy property of degree, we obtain that

$$
\begin{aligned}
\operatorname{deg}\left(\left.J Q N\right|_{\text {ker } L}, \Omega \cap \operatorname{ker} L, 0\right) & =\operatorname{deg}(H(\cdot, 0), \Omega \cap \operatorname{ker} L, 0) \\
& =\operatorname{deg}(H(\cdot, 1), \Omega \cap \operatorname{ker} L, 0) \\
& =\operatorname{deg}( \pm I, \Omega \cap \operatorname{ker} L, 0) \neq 0 .
\end{aligned}
$$

Applying Theorem 2.1, we conclude that $L u=N u$ has at least one solution in $\operatorname{dom} L \cap \bar{\Omega}$. 


\section{Some examples}

To illustrate how our main results can be used in practice, we present three examples.

Example 4.1 Let us consider the following boundary value problem:

$$
\left\{\begin{array}{l}
D_{0^{+}}^{2.5} u(t)=\frac{t}{2}+e^{-u^{2}(t)}+\frac{1}{6}\left|D_{0^{+}}^{1.5} u(t)\right|+\cos \left(D_{0^{+}}^{0.5} u(t)\right), \quad 0<t<1, \\
u(0)=u^{\prime}(0)=0 \\
u(1)=\frac{5}{2} \int_{0}^{1} u(t) d t
\end{array}\right.
$$

By the calculation, we can have $A=B=7$ and $\left(\mathrm{H}_{0}\right)-\left(\mathrm{H}_{4}\right)$ are all satisfied. Hence, we obtain that (4.1) has at least one solution.

Example 4.2 Consider the following integral boundary value problem:

$$
\left\{\begin{array}{l}
D_{0^{+}}^{3.6} u(t)=t^{2}+\arctan u(t)+\frac{1}{10} D_{0^{+}}^{2.6} u(t)+\cos \left(D_{0^{+}}^{0.6} u(t)\right)+\sin \left(D_{0^{+}}^{1.6} u(t)\right), \quad 0<t<1, \\
u(0)=u^{\prime}(0)=u^{\prime \prime}(0)=0 \\
u(1)=\frac{23}{5} \int_{0}^{1} t \cdot u(t) d t
\end{array}\right.
$$

It is easy to see that $\left(\mathrm{H}_{0}\right)-\left(\mathrm{H}_{4}\right)$ hold. By a simple calculation, we can have $A=48, B=14$. Thus it follows that problem (4.2) has at least one solution.

Example 4.3 We consider the boundary value problem

$$
\left\{\begin{array}{l}
D_{0+}^{1.2} u(t)=\cos (t+1)^{2}+\frac{1}{8} \sin u(t)+\frac{1}{9} D_{0+}^{0.2} u(t), \quad 0<t<1 \\
u(0)=0 \\
u(1)=\frac{16}{5} \int_{0}^{1} t^{2} u(t) d t
\end{array}\right.
$$

Corresponding to problem (1.1), we have that $\alpha=1.2, m=2$. By a simple calculation, we can get $A=11, B=12$, then $\left(\mathrm{H}_{0}\right)-\left(\mathrm{H}_{4}\right)$ hold. By Theorem 3.1, we obtain that (4.3) has at least one solution.

\section{Conclusion}

In this paper, we have obtained the existence of solutions for fractional differential equations with integral boundary conditions at resonance. By using the coincidence degree theory, we have found the existence results. Though the technique applied to establish the existence results for the problem is a standard one, yet its results are new in the context of integral boundary conditions. As applications, three examples are presented to illustrate the main results. In the future, we will consider the uniqueness of solutions for the fractional differential equations at resonance, and also can make further research on fractional differential equations with a singular integral boundary value problem at resonance.

The authors declare that they have no competing interests. 


\section{Author details}

${ }^{1}$ Department of Mathematics, China University of Mining and Technology, Beijing, 100083, China. ${ }^{2}$ School of Science, Shandong Jiaotong University, Jinan, 250357, China. ${ }^{3}$ School of Science, Beijing University of Civil Engineering and Architecture, Beijing, 100044, China.

\section{Acknowledgements}

The authors are grateful to the reviewers for their valuable suggestions and detailed comments which have improved the paper very much. This research is supported by the Natural Science Foundation of China (11371364) and 2013 Science and Technology Research Project of Beijing Municipal Education Commission (KM201310016001).

\section{Received: 8 June 2013 Accepted: 6 November 2013 Published: 03 Dec 2013}

\section{References}

1. Kilbas, AA, Srivastava, HM, Trujillo, JJ: Theory and Applications of Fractional Differential Equations. Elsevier, Amsterdam (2006)

2. Samko, SG, Kilbas, AA, Marichev, Ol: Fractional Integral and Derivatives (Theory and Applications). Gordon \& Breach, Switzerland (1993)

3. Podlubny, I: Fractional Differential Equations. Academic Press, New York (1999)

4. Baleanu, D, Mohammadi, H, Rezapour, S: Some existence results on nonlinear fractional differential equations. Philos. Trans. R. Soc. Lond. Ser. A, Math. Phys. Sci. 371, 20120144 (2013)

5. Baleanu, D, Agarwal, RP, Mohammadi, H, Rezapour, S: Some existence results for a nonlinear fractional differential equation on partially ordered Banach spaces. Bound. Value Probl. 2013, 112 (2013)

6. Zhang, S: Positive solutions for boundary value problems of nonlinear fractional differential equations. Electron. J. Differ. Equ. 36, 1-12 (2006)

7. Baleanu, D, Mohammadi, $H$, Rezapour, S: Positive solutions of a boundary value problem for nonlinear fractional differential equations. Abstr. Appl. Anal. 2012, Article ID 837437 (2012)

8. Baleanu, D, Mohammadi, $H$, Rezapour, S: On a nonlinear fractional differential equation on partially ordered metric spaces. Adv. Differ. Equ. 2013, 83 (2013)

9. Cabadaa, A, Wang, G: Positive solutions of nonlinear fractional differential equations with integral boundary value conditions. J. Math. Anal. Appl. 389, 403-411 (2012)

10. Yuan, C: Two positive solutions for $(n-1, n)$-type semipositone integral boundary value problems of coupled systems of nonlinear fractional differential equations. Commun. Nonlinear Sci. Numer. Simul. 17, 930-942 (2012)

11. Feng, M, Zhang, X, Ge, W: New existence results for higher-order nonlinear fractional differential equation with integral boundary conditions. Bound. Value Probl. 2011, Article ID 720702 (2011)

12. Jiang, $\mathbf{W}$ : The existence of solutions to boundary value problems of fractional differential equations at resonance. Nonlinear Anal. 74, 1987-1994 (2011)

13. Kosmatov, N: Multi-point boundary value problems on an unbounded domain at resonance. Nonlinear Anal. 68, 2158-2171 (2008)

14. Kosmatov, N: A boundary value problem of fractional order at resonance. Electron. J. Differ. Equ. 135, 1-10 (2010)

15. Bai, Z: Solvability for a class of fractional m-point boundary value problem at resonance. Comput. Math. Appl. 62 , 1292-1302 (2011)

16. Bai, Z, Zhang, Y: Solvability of fractional three-point boundary value problems with nonlinear growth. Appl. Math. Comput. 218, 1719-1725 (2011)

17. Zhang, Y, Bai, Z: Existence of solutions for nonlinear fractional three-point boundary value problems at resonance. J. Appl. Math. Comput. 36, 417-440 (2011)

18. Mawhin, J: Topological degree methods in nonlinear boundary value problems. In: NSF-CBMS Regional Conference Series in Math, vol. 40. Am. Math. Soc., Providence (1979)

10.1186/1687-1847-2013-353

Cite this article as: Zhang et al.: Existence result for a nonlinear fractional differential equation with integral

boundary conditions at resonance. Advances in Difference Equations 2013, 2013:353

\section{Submit your manuscript to a SpringerOpen ${ }^{\ominus}$ journal and benefit from:}

- Convenient online submission

- Rigorous peer review

- Immediate publication on acceptance

- Open access: articles freely available online

- High visibility within the field

- Retaining the copyright to your article 